\title{
Alfred de Musset, La Confessione di un figlio del secolo
}

\section{Valentina Ponzetto}

\section{(2) OpenEdition}

\section{Journals}

\section{Edizione digitale}

URL: https://journals.openedition.org/studifrancesi/40971

DOI: 10.4000/studifrancesi.40971

ISSN: 2421-5856

\section{Editore}

Rosenberg \& Sellier

\section{Edizione cartacea}

Data di pubblicazione: 1 juillet 2004

Paginazione: 212-213

ISSN: 0039-2944

Notizia bibliografica digitale

Valentina Ponzetto, «Alfred de Musset, La Confessione di un figlio del secolo», Studi Francesi [Online], 142 (XLVIII | I) | 2004, online dal 30 novembre 2015, consultato il 09 septembre 2021. URL: http:// journals.openedition.org/studifrancesi/40971 ; DOI: https://doi.org/10.4000/studifrancesi.40971

Questo documento è stato generato automaticamente il 9 septembre 2021 .

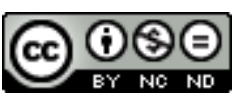

Studi Francesi è distribuita con Licenza Creative Commons Attribuzione - Non commerciale - Non opere derivate 4.0 Internazionale. 


\title{
Alfred de Musset, La Confessione di un figlio del secolo
}

\author{
Valentina Ponzetto
}

\section{NOTIZIA}

ALFRED DE MUSSET, La Confessione di un figlio del secolo, a cura di Franco D'INTINO, traduzione di Alessandra TERNI, Roma, Fazi, 2003, pp. 316.

1 Come recita chiaramente il sottotitolo della sua Postfazione Franco D'Intino pone La Confessione sotto il segno di Faust, «un Faust in maschera».

2 Nel secondo capitolo del romanzo, grande affresco collettivo di un'intera generazione, o, per dirlo col critico, "saggio di storia sociale e intellettuale», Goethe è in effetti evocato insieme a Byron come uno dei «due più bei geni del secolo dopo Napoleone», «il patriarca di una nuova letteratura» e al tempo stesso un punto di non ritorno, colui che ha spinto fino al limite estremo i confini della ragione umana e l'ideale di dubbio universale del secolo dei Lumi. Faustiano potrà dunque essere considerato l'eroe di Musset, corruttore, disincantato e disperato, per cui la conoscenza è curiosità del male e perdita dell'innocenza, il cielo è vuoto e lo svelamento della verità o della realtà si accompagna a immagini agghiaccianti di morte e di orrore, quasi citazioni del sabba goethiano. Tuttavia Octave, e gli altri «figli del secolo» con lui, sono per D'Intino l'immagine di un "eroe faustiano "ignobile"», roso dall'incertezza e dall'ambiguità, privato di forza vitale e come paralizzato dalla catastrofe meschina della Restaurazione, che rende impossibile sia il tornare indietro, verso un passato perduto, sia l'andare avanti. Un eroe, per giunta, con ben poco di eroico, che verrebbe quasi meccanicamente spinto dall'autore in principio verso la prima disillusione, la scoperta dell'infedeltà della prima amante, poi verso la continua ripetizione di quel trauma. Per recuperare il passato a cui guarda con rimpianto non gli resta dunque che la ripetizione parodistica, il rovesciamento, dapprima con il travestimento della prostituta, poi, nella terza parte, con il tentativo di imitatio patris. Ecco, dunque, un primo perché della maschera. 
3 Ma un rovesciamento o un mascheramento del modello goethiano si può individuare, secondo il critico, anche nella struttura stessa del racconto : seguendo a ritroso il percorso che aveva portato il poeta tedesco dal Werther al Faust, infatti, Musset fa seguire alla sorta di discesa negli inferi della dissolutezza della seconda parte l'idillio campestre della terza, che vede lo sbocciare dell'amore fra Octave e Brigitte-la-Rose. In quest'ultima D'Intino vede un riflesso della Gretchen del Faust, un'allegoria della salvezza, figura mariana della donna pura che sola può intercedere per il protagonista. Anche in questo caso tuttavia la struttura faustiana risulta rovesciata : laddove la «pedagogia illuministica goethiana» conduceva Faust alla salvezza finale, per Musset la salvezza non è mai definitiva e la quarta parte della Confession non fa che rigettare Octave - e Brigitte con lui - in una spirale di dubbio, di gelosia e di menzogna, spingendo il romanzo verso un'assenza di vera conclusione.

4 Maschera in effetti è anche la menzogna, o la finzione, onnipresente in questo romanzo che pure si vorrebbe racconto veritiero, come indica già il titolo stesso di Confessione, con i suoi echi rousseauiani e prima ancora agostiniani. Spingendosi ben oltre i suoi illustri predecessori Musset trascina il lettore in un gioco ambiguo e perverso, in cui sincerità è mostrare che la malattia del secolo è una vita fatta di ambiguità, artificio, ipocrisia, quindi romanzo. Ecco dunque che egli costruisce, a partire dal materiale autobiografico della propria relazione con George Sand, di cui a tratti sono riconoscibili persino i dettagli, un romanzo che si propone esplicitamente come opera di finzione, il cui protagonista - io narrante, non esita per giunta a confessare il piacere della narrazione menzognera.

Del resto, ennesimo ritorno del tema della maschera, ogni pagina della Confessione è secondo D'Intino fittamente intessuta di letteratura perché piena di citazioni e di allusioni ad altre opere, o di espressioni e situazioni che paiono la ripresa e l'esagerazione di luoghi comuni del romanzo romantico. Siamo insomma, nota giustamente il critico, di fronte ad un «libro pieno di libri». Così ai tanti autori già chiamati in causa da Musset egli non esita ad aggiungerne altri - Carlyle, Leopardi, Lermontov, Stendhal, persino accenni a Gide o a Svevo - in un ampio e vario dispiego di intertestualità comparatistica che, pur restando pertinente, rischia a tratti di sviare l'attenzione del lettore dal testo mussettiano più che di guidarne l'interpretazione.

6 In questo sottolineare il trionfo del cliché e del déjà vu come cifra stilistica è anche l'apporto forse più stimolante che ci venga qui proposto, quello che mette in luce l'aspetto più moderno della scrittura mussettiana. I temi del linguaggio come abito composito o come prostituta, l'invasione del luogo comune come imitazione di un gesto linguistico del passato, che tende a confondere l'individuo in un io collettivo, il virtuosismo con cui Musset da questa raccolta di materiali compositi riesca a crearsi uno stile originale sono infatti tutti spunti che anticipano non solo i flaubertiani Buvard e Pécuchet, ma le riflessioni di tanta letteratura del Novecento. Possiamo dunque cogliere in queste pagine anche un invito a (ri)leggere La Confessione come un romanzo a noi vicino, senza fermarci alla lettera, a dire il vero spesso pesantemente «romantica» del testo.

7 Forse appunto perché destinato ad essere fruito per il piacere della lettura da un pubblico non specialistico il romanzo è accompagnato da un apparato estremamente agile, comprendente una succinta nota biografica su Musset, una bibliografia delle edizioni di riferimento dei suoi testi in originale e in traduzione italiana ed infine poche note (35 in tutto) che si limitano per lo più a segnalare l'identità di qualche 
personaggio, la provenienza di citazioni letterarie o musicali, la natura e la localizzazione di alcuni riferimenti parigini 